\title{
Glutamic acid decarboxylase antibodies, autonomic nerve antibodies and autonomic neuropathy in diabetic patients
}

\author{
G. Sundkvist ${ }^{1}$, L.A. Velloso ${ }^{2}$, O. Kämpe ${ }^{2}$, S.L Rabinowe ${ }^{3}$, S. A. Ivarsson ${ }^{4}$, B. Lilja ${ }^{5}$, F. A. Karlsson ${ }^{2}$ \\ ${ }^{1}$ Department of Medicine, University of Lund, Malmö General Hospital, Malmö, Sweden \\ ${ }^{2}$ Department of Medicine, University of Uppsala, University Hospital, Uppsala, Sweden \\ ${ }^{3}$ Immunology Section, Joslin Diabetes Center, Brigham and Women's Hospital, Harvard Medical School, Boston, Massachusetts, \\ USA \\ ${ }^{4}$ Department of Pediatrics, University of Lund, Malmö General Hospital, Malmö, Sweden \\ ${ }^{5}$ Department of Clinical Physiology, University of Lund, Malmö General Hospital, Malmö, Sweden
}

\begin{abstract}
Summary To clarify whether GAD-ab are associated with diabetic autonomic neuropathy and/or complement fixing antibodies against sympathetic ganglia, adrenal medulla, and vagus nerve, we examined 133 diabetic patients (95 with IDDM). GAD-ab were determined by a radioligand binding assay using in vitro expression of recombinant GAD-65 whereas sympathetic ganglia antibodies, adrenal medulla antibodies, vagus nerve, and ICA were evaluated by indirect immunofluorescence assays. Autonomic nerve function was evaluated by objective tests (heart rate reactions to deep breathing and to tilt). In the total material of 133 patients, GAD-ab were detected in 36 patients, all of whom had IDDM. The frequency of GADab was similar (38\%) in IDDM patients with and without signs of autonomic neuropathy (21 of 55 vs 15 of 40). In addition, there were no significant associations between GAD-ab and autonomic nerve antibodies;
\end{abstract}

GAD-ab were detected in 9 of $21(43 \%)$ of patients with and in 27 of $112(24 \%)$ of patients without sympathetic ganglia antibodies, in 5 of $15(33 \%)$ of patients with and 31 of $118(26 \%)$ without adrenal medulla antibodies, and in 5 of $15(33 \%)$ with and 31 of $118(26 \%)$ of patients without vagus nerve antibodies. The frequency of ICA, however, was significantly increased in patients with sympathetic ganglia antibodies compared with those without sympathetic ganglia antibodies (10 of $21[48 \%]$ vs 21 of $112[19 \%] ; p<0.01$ ). In conclusion, GAD-ab were neither associated with disturbed autonomic nerve function nor with antibodies against autonomic nerve structures. [Diabetologia (1994) 37: 293-299]

Key words Autonomic neuropathy, glutamic acid decarboxylase antibodies, sympathetic nerve antibodies, vagal nerve antibodies, islet cell antibodies.
Antibodies reacting with glutamic acid decarboxylase (GAD-ab) [1], possibly synonymous with islet $64 \mathrm{~K}$ protein antibodies (64 K-ab) [2], can be detected years before the clinical onset of IDDM [3]. ICA may also

Received: 12 July 1993
and in revised form: 4 October 1993

Corresponding author: Dr. G. Sundkvist, Department of Medicine, Malmö General Hospital, S-214 01 Malmö, Sweden

Abbreviations: GAD, Glutamic acid decarboxylase; ab, antibodies; ICA, islet cell antibodies; CF-ADM, complement-fixing adrenal medulla antibodies; CF-SG, complement-fixing sympathetic ganglia antibodies; $\mathrm{CF}-\mathrm{V}$, complement-fixing vagal nerve antibodies; IDDM, insulin-dependent diabetes mellitus; NIDDM, non-insulin-dependent diabetes mellitus; JDF, Juvenile Diabetes Foundation precede the clinical onset of IDDM [4] and are detected in most IDDM patients at the time of their clinical diagnosis [5]. ICA usually disappear during the initial years following diagnosis [6-8] whereas GAD-ab and/or $64 \mathrm{~K}$-ab seem to be more persistent [9-12]. GAD catalyses the formation of gamma-aminobutyric acid, a major neuro-inhibitor present in the central nervous system but also in pancreatic nerves [13]. Therefore, when persistent GAD-ab were detected in IDDM patients with neuropathy and particular high levels of GAD-ab were observed in patients with autonomic neuropathy, Kaufman et al. [11] proposed that GAD-ab may be associated with diabetic neuropathy. The hypothesis that autoimmunity could be linked to diabetic neuropathy is supported by other observations [14-17] including reports of CF-ADM [18], CF-SG [19], and CF-V [20] in IDDM as well as in NIDDM pa- 
tients [21]. Autonomic neuropathy is frequently observed in NIDDM patients [22]; if autoimmunity is associated with autonomic neuropathy, NIDDM should be considered. To clarify the possible association between GAD-ab and autonomic neuropathy, in a crosssectional study we have determined GAD-ab and ICA in diabetic patients and related the results to autonomic nerve function and autonomic nerve antibodies. In addition, a group of prospectively followed IDDM patients was assessed. The aims of the current report were to relate GAD-ab and ICA to autonomic nerve function and to CF-SG, CF-ADM, and CF-V in diabetic patients, to test whether these antibodies in prospectively followed patients predicted the development of autonomic neuropathy, and to evaluate whether analysis of the additional data would clarify our previous paradoxical finding [21] of preserved autonomic nerve function in diabetic patients with CF-SG and CF-ADM.

\section{Subjects, materials, and methods}

Patients. From the previously described study [21] a total of 111 patients had sera available for analysis of GAD-ab and autonomic nerve antibodies; 73 (33 women) had IDDM (age 2077 years [mean age \pm SEM, $42 \pm 2$ years], duration of diabetes $2-62$ years [mean $23 \pm 2$ years]) and 38 ( 6 women) had NIDDM (age 42-59 years [mean 50 \pm 1 years]; duration of diabetes $3-$ 17 years [mean $9 \pm 1$ years]). In the new prospective study, 22 IDDM patients ( 15 women), from whom sera had been obtained and frozen 10-13 years before the current study, were evaluated with regard to both autonomic nerve function and a recently obtained serum sample; age range in the current study 18-31 years, mean $25 \pm 7$; duration of diabetes 5-28 years, mean $15 \pm 1$ (one patient with a duration of 5 years had a serum sample taken and stored 5 years before the diagnosis of clinical diabetes). In the cross-sectional part of the current study, autonomic nerve function was related to autoantibodies in the total material (133 patients; the original 111 patients together with the 22 prospective patients).

$G A D-a b$ assay. GAD-ab were determined by a radioligand binding assay using in vitro expression of recombinant rat GAD 65 in an eukaryotic system as previously described [23]. The expressed enzyme was labelled with ${ }^{35} \mathrm{~S}$-methionine and purified by ion exchange and affinity chromatography. The purified GAD was finally incubated with serum to be analysed and the immunocomplexes were precipitated using a preparation of $20 \%$ Staphylococcus aureus (Cowan strain 1). In each set of experiments, incubations with a positive standard patient sera (given the arbitrary titre of $100 \mathrm{U} / 1$ ) as well as five negative control serum were included. The results of unknown serum samples were analysed and given in GAD index, which is based on the following method of calculation: Unknown sample (cpm, mean of duplicate) - negative control (cpm, mean of duplicate) divided by positive control (cpm, mean of duplicate) - negative control (cpm, mean of duplicate) multiplied by a factor 100 . The inter-assay coefficient of variation was $6.7 \%$. For inter-assay comparison the GAD index was divided by the mean value of controls $(n=5)+2 \mathrm{SD}$. This final value is presented as corrected GAD index and an index greater than 1 is considered as positive; the upper reference range (mean $+2 \mathrm{SD}$ ) was defined from data obtained by precipitations using sera from 20 healthy control subjects [23].
ICA assay. Unfixed human blood group " 0 " pancreas from a single donor was used in an indirect two-colour immunofluorescence assay [24]. Serum samples were diluted $1: 2,1: 4,1: 8$, etc, and the end-point titre was defined as the highest titre with detectable ICA. ICA levels are presented in JDF units based upon titration of the JDF standard serum on the single pancreas used throughout the study. The inter-assay variation was 0.65 titration steps during the study period. The detection limit for used pancreas was $3 \mathrm{JDF}$ units.

Assays for $C F$ nerve antibodies. Indirect immunofluorescence complement-fixation techniques were used in all three assays. Human adrenal gland obtained at surgery or autopsy was used in CF-ADM, rabbit sympathetic ganglia in CF-SG, and rabbit vagal nerve in CF-V. The assays have been described in detail [18-20]. In the case of CF-SG and CF-V binding has been previously demonstrated with human tissue eliminating the question of a heterophilic antibody binding. Fresh human serum was used as a complement source. Fluorescein isothiocyanate goatanti-human C3c (Calbiochem-Behring, LaJolla, Calif., USA) was used as the detecting agent. For CF-ADM, a fluorescence score of 4 , and for CF-SG as well as CF-V, a score of 1 or above were considered abnormal. In normal control subjects, the frequency of $\mathrm{CF}-\mathrm{SG}$ is $0 \%, \mathrm{CF}-\mathrm{ADM}, 3 \%$, and $\mathrm{CF}-\mathrm{V}, 0 \%$ [25].

Autonomic nerve function was assessed from the heart rate reactions to deep breathing (expiration/inspiration ratio, a test of parasympathetic nerve function) [26] and to tilt (acceleration and brake indices, tests considering sympathetic nerve function as well) [27]. The blood pressure reaction to tilt was also assessed as a test of sympathetic nerve function. Only objective tests of autonomic nerve function were employed; symptoms of autonomic neuropathy are difficult to validate [22]. To match for the influence of age on autonomic nerve function, autonomic indices were transformed into age-corrected values expressed as SD. Autonomic neuropathy was defined as at least one autonomic neuropathy index less than 1.5 SD below the age-related reference value for the expiration/inspiration ratio, acceleration, and/or the brake index [22]. Informed consent was obtained from all subjects and the study was conducted according to the Declaration of Helsinki.

\section{Statistical analysis}

Differences in frequency were tested with the chi-square test with contiguency correction or Fisher's exact test, differences between groups with the Mann-Whitney U-test, differences within groups with the Wilcoxon paired test, and Spearman's test was used for correlations. All tests were two-tailed and a $p$ value less than 0.05 was considered significant. Values are presented as mean \pm SEM.

\section{Results}

\section{Cross-sectional study (total material)}

In the total material, autonomic neuropathy was found in 79 of $133(59 \%)$ patients; 55 of $95(58 \%)$ with IDDM and 24 of $38(63 \%)$ with NIDDM showed autonomic neuropathy (Table 1 ). There were no significant differences in age and duration of diabetes between patients with and without autonomic neuropathy among IDDM or NIDDM patients. 
Table 1. Frequencies of GAD-ab, ICA, CF-SG, CF-ADM, and CF-V in diabetic patients with and without autonomic neuropathy

\begin{tabular}{|c|c|c|c|c|c|c|}
\hline & \multicolumn{2}{|c|}{ All diabetic patients } & \multicolumn{2}{|l|}{ IDDM } & \multicolumn{2}{|l|}{ NIDDM } \\
\hline & $\begin{array}{l}\text { with } \\
\text { neuropathy }\end{array}$ & $\begin{array}{l}\text { without } \\
\text { neuropathy }\end{array}$ & $\begin{array}{l}\text { with } \\
\text { neuropathy }\end{array}$ & $\begin{array}{l}\text { without } \\
\text { neuropathy }\end{array}$ & $\begin{array}{l}\text { with } \\
\text { neuropathy }\end{array}$ & $\begin{array}{l}\text { without } \\
\text { neuropathy }\end{array}$ \\
\hline GAD- $a b^{f}$ & 21 [27] & $15[28]$ & 21 [38] & $15[38]$ & 0 & 0 \\
\hline $\mathrm{ICA}^{\mathrm{g}}$ & 18 [23] & $13[24]$ & 16 [29] & $13[33]$ & $2[8]$ & 0 \\
\hline $\mathrm{CF}-\mathrm{SG}$ & $5[6]$ & $16[30]^{a}$ & $3[5]$ & $14[35]^{a}$ & $2[8]$ & $2[14]$ \\
\hline
\end{tabular}

Values in brackets are \%. ${ }^{a} p<0.001$ compared with patients with neuropathy; ${ }^{b}$ Age: $36 \pm 1$ years; duration of diabetes $19 \pm$ 1 years; ${ }^{c}$ age $41 \pm 3$ years; duration of diabetes $23 \pm 3$ years; d age: $50 \pm 1$ years; duration of diabetes $9 \pm 1$ years; ${ }^{\mathrm{e}}$ age: $49 \pm$ 1 years; duration of diabetes $9 \pm 1$ years; ${ }^{\mathrm{f}}$ IDDM patients with GAD-ab compared with those without; age: $36 \pm 3$ [range 18-77]

In the total material, GAD-ab were found in 36 patients, all of whom had IDDM. GAD-ab were not associated with autonomic neuropathy; 21 of $55(38 \%)$ IDDM patients with and 15 of $40(38 \%)$ IDDM patients without autonomic neuropathy showed GAD-ab (Table 1). There were no significant differences in age and duration of diabetes between IDDM patients with and without GAD-ab.

In the total material, ICA were noted in 31 of 133 $(23 \%)$ patients, most of them (29 of $31 ; 94 \%$ ) with IDDM. As for GAD-ab, the frequency of ICA did not differ significantly between IDDM patients with and without autonomic neuropathy (16 of 55 [29\%] vs 13 of 40 [33\%], respectively). IDDM patients with GAD-ab showed a significantly higher frequency of ICA than IDDM patients without GAD-ab (19 of 36 [53\%] vs 10 of $59[17 \%] ; p<0.001)$. There was a tendency for GAD-ab positivity to be more frequent than ICA positivity in IDDM patients with a long duration of diabetes (Fig. 1a); however, four patients with a duration of diabetes of more than 20 years showed ICA without GAD-ab (Fig. 1b; ICA levels in those four cases $3,8,12$, and $30 \mathrm{JDF}$ units, respectively). It is noteworthy that four patients with a diabetes duration of more than 40 years had GAD-ab; two of whom were also ICA positive (Fig. 1 a; patients without ICA; corrected GAD indices 4.84 and 8.91, respectively; patients with ICA: ICA 116 JDF units with a corrected GAD-ab index of 22.49 and ICA 705 JDF units with a corrected GAD-ab index of 13.16 , respectively). In GAD-ab positive patients, the corrected GAD index correlated significantly with ICA levels (Fig. $2, r=0.53$; $p<0.002)$ but not as expected with the duration of diabetes $(r=0.23 ; p=0.14)$.

In the total material, CF-SG were detected in 21 of $133(16 \%$ ) patients (Table 1$)$. CF-SG were significantly $(p<0.001)$ less frequent in patients with than in patients without autonomic neuropathy. In agreement with this observation, the acceleration index $(-0.29 \pm$ 0.23 vs $-1.00 \pm 0.09$, respectively; $p<0.01)$ and the brake index $(-0.33 \pm 0.20$ vs $-0.95 \pm 0.09$, respectively, years vs $39 \pm 2$ [range 18-73] years, respectively; duration of diabetes: $19 \pm 2$ [range $4-56$ ] years vs $22 \pm 2$ [range $2-62$ ] years, respectively. $\mathrm{g}$ IDDM patients with ICA compared with those without; age $37 \pm 2$ years vs $38 \pm 2$ years, respectively; duration of diabetes: $18 \pm 2$ years vs $22 \pm 2$ years, respectively
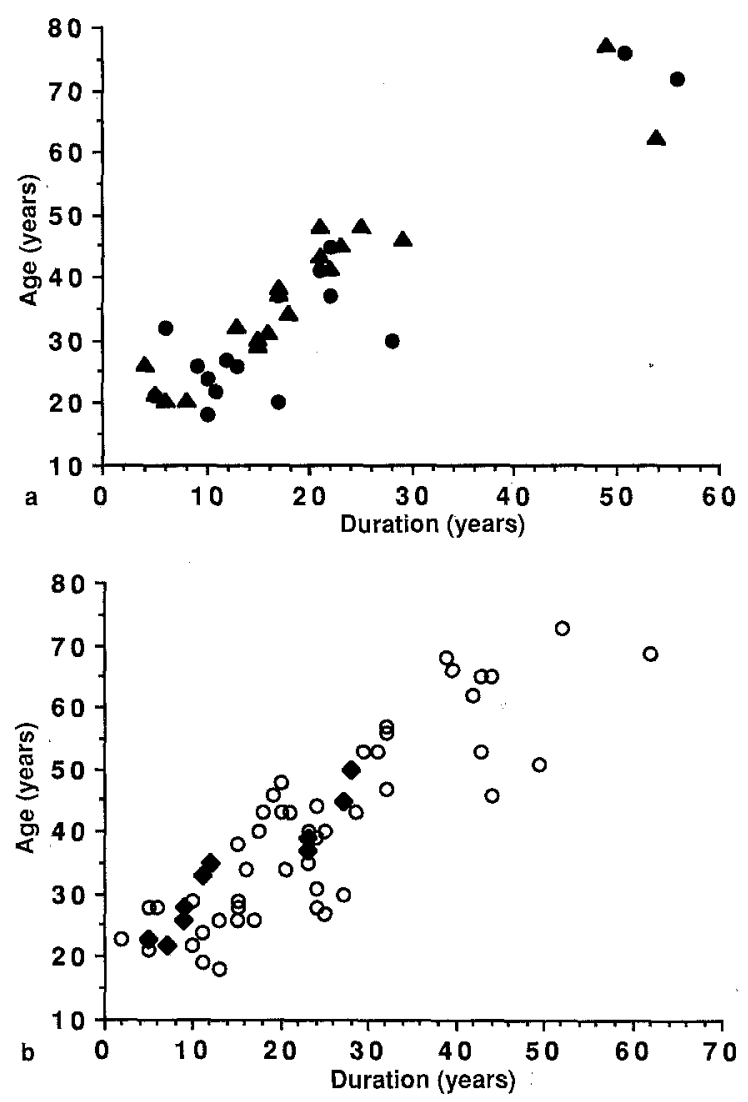

Fig. 1 a, b. (a) Patients with IDDM with GAD-ab in relation to the duration of diabetes and age. patients with ICA and GAD-ab (b) IDDM patients without GAD-ab in relation to the duration of diabetes and age. $O$, patients without GAD-ab; $\diamond$, patients with ICA but without GAD-ab

$p<0.002$ ) were significantly higher (more normal) in patients with than in patients without CF-SG. The frequency of ICA, but not of GAD-ab, was significantly higher in IDDM patients with CF-SG than in IDDM patients without CF-SG (ICA: 10 of 17 [59\%] vs 19 of 78 [24\%], $p<0.02$; GAD-ab: 9 of 17 [53\%] vs 27 of 78 $[35 \%], p=0.26)$. In IDDM patients, CF-SG levels 


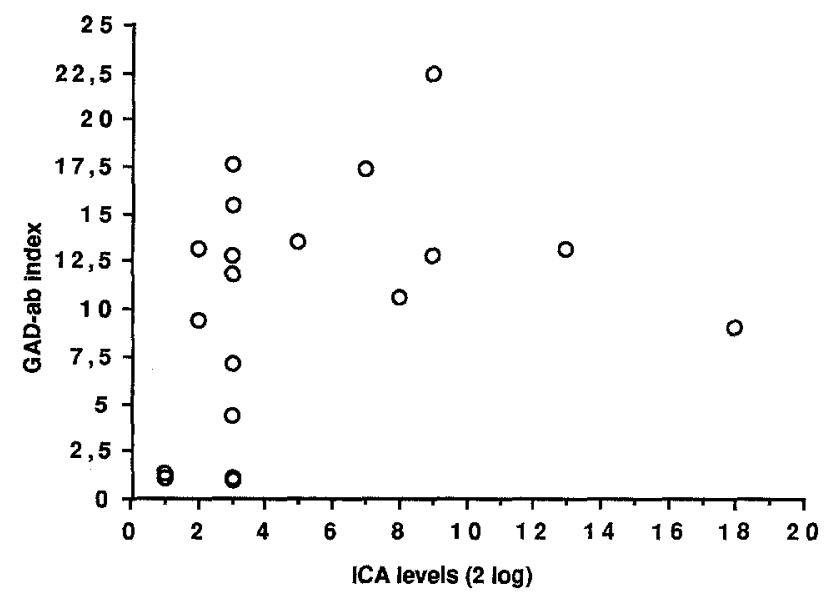

Fig. 2. GAD-ab levels (corrected GAD-ab index) in relation to levels of ICA in GAD-ab positive IDDM patients

correlated significantly with ICA levels (Fig. 3: $r=0.42$; $p<0.001)$ but not with the corrected GAD index $(r=$ $0.19 ; p=0.10$ ).

In the total material, CF-ADM were found in 15 of $133(11 \%)$ patients and the frequency was not influenced by the type of diabetes (Table 1). In IDDM patients a possible association between CF-ADM and autonomic failure was detected; although the autonomic nerve test indices did not differ significantly (data not shown) between patients with and without CF-ADM, diastolic blood pressure was significantly lower $8 \mathrm{~min}$ after tilt ( $70 \pm 9$ vs $84 \pm 1 \mathrm{~mm} \mathrm{Hg} ; p<0.05$ ) in those with than in those without CF-ADM. There were no obvious associations for CF-ADM vs GAD-ab and ICA; GAD were detected in 5 of $15(33 \%)$ patients with, vs 31 of $118(26 \%)$ patients without CF-ADM, corresponding frequencies for ICA were 5 of $15(33 \%)$ vs 26 of $118(22 \%)$.

In the total material, CF-V were present in 15 of 133 $(11 \%)$ patients and tended, as previously described [21], to be associated with autonomic neuropathy in NIDDM patients (Table 1). There were no obvious associations for CF-V vs GAD-ab and ICA; GAD were detected in 5 of $15(33 \%)$ patients with vs 31 of 118 $(26 \%)$ patients without $\mathrm{CF}-\mathrm{V}$, corresponding frequencies for ICA were 4 of $15(27 \%)$ vs 27 of $118(23 \%)$.

\section{Clusters of antibodies}

Amongst IDDM patients, 21 had antibodies against one autonomic nerve ( 12 with CF-SG, five with CFADM, and three with CF-V; together with ICA and GAD-ab in five cases, with ICA alone in two cases, and with GAD-ab alone in three cases), six had antibodies against two autonomic nerves (CF-SG and CF-ADM in two cases, CF-SG and CF-V in two cases, and CF$A D M$ and CF-V in two cases; together with ICA and GAD-abs in two cases, ICA alone in two cases, and

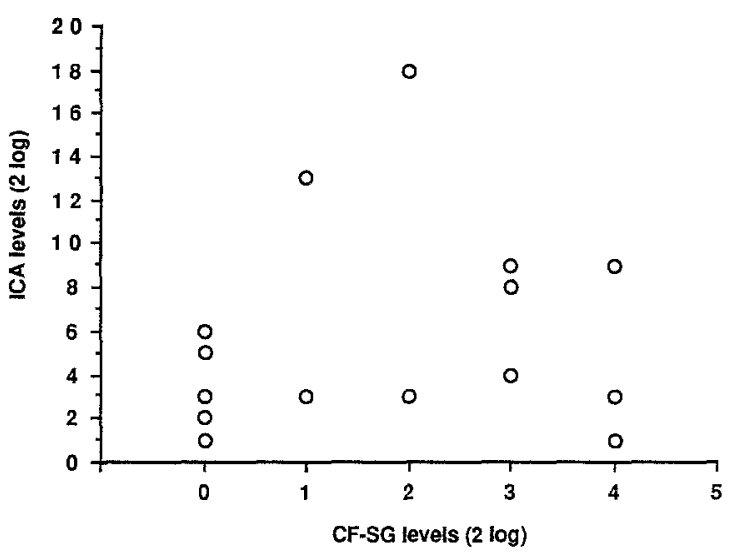

Fig.3. Levels of ICA in relation to levels of CF-SG in IDDM patients

GAD-ab alone in two cases) whereas all three autonomic nerve antibodies were detected in one patient (together with ICA and GAD-ab). Amongst NIDDM patients, nine showed antibodies against one autonomic nerve (CF-SG in two cases, CF-ADM in three cases, and CF-V in four cases; CF-V were combined with ICA in one case) whereas three patients showed antibodies against two autonomic nerves (CF-SG and CF-ADM, CF-SG and CF-V, and CF-ADM and CF-V; no association with ICA). A combination of three autonomic nerve antibodies was not detected in any of the NIDDM patients.

\section{Prospective study}

In the 22 prospectively-followed IDDM patients, 9 of 20 (45\%; sera lacking in two patients) had GAD-ab in the first study and in the second study 6 of 9 of them had become GAD-ab negative. However, five previously GAD-ab negative patients were GAD-ab positive in the second study. Hence, nine patients were GAD-ab positive in the second study (1 of 2 patients without sera in the first study was GAD-ab positive in the second study).

ICA were detected in three patients in the first study (levels 183,19 , and $5 \mathrm{JDF}$ units, respectively) and 2 of 3 were ICA negative in the second study; the patient still positive had increased his ICA levels (from 19 to $47 \mathrm{JDF}$ units). All three of the ICA positive patients were positive for GAD-ab in the first study and their GAD-ab levels and ICA levels were well correlated (patient 1: ICA level $=183 \mathrm{JDF}$ units, corrected GAD index $=14.77$; patient 2 ICA lev$\mathrm{el}=19 \mathrm{JDF}$ units, corrected GAD-ab index $=4.58$; patient 3 ICA level $=5$ JDF units, corrected GAD-ab index $=1.63$ ). Patients 1 and 3 became ICA negative in the second study and, in agreement with this, the GAD indices in these patients decreased (patient 1 
from 14.77 to 1.26 ; patient 3 from 1.63 to 0.99 i.e. patient 3 was GAD-ab negative in the second study). Interestingly, patient 2, who showed an increase in ICA levels between the studies, displayed a corresponding increase in the corrected GAD-ab index (from 4.58 in the first study to 17.44 in the second).

There were no significant differences in autonomic nerve function tests between patients with and without GAD -ab (data not shown).

In the first study, CF-SG were detected in one patient, CF-V in another, whereas CF-ADM were not detected in any patient. In the second study, CF-SG had disappeared in the patient who was previously CF-SG positive; however, CF-SG were now detected in three other patients, CF-ADM had appeared in two patients, whereas CF-V persisted in the patient previously CF-V positive. No obvious clinical specific features were detected in the patients with CF-SG and CF-V. The two patients with CF-ADM had low brake indices $(-2.77$ and -2.59 , respectively); the mean brake index was significantly lower in these patients compared with the other 20 patients $(-2.68 \pm 0.09$ vs $-0.79 \pm 0.33$, respectively; $p<0.05$ ). In addition, one of the CF-ADM positive patients demonstrated profound systolic and diastolic blood pressure falls $8 \mathrm{~min}$ after tilt (blood pressures recorded as $0 \mathrm{~mm} \mathrm{Hg}$ ).

\section{Discussion}

This study failed to demonstrate a relationship between GAD-ab and autonomic neuropathy. In addition, no association between GAD-ab and autonomic nerve antibodies (CF-SG, CF-ADM, and CF-V) was discovered and none of the antibodies tested predicted future deteriorations in autonomic nerve function. The presence of CF-SG was found to be associated with preserved autonomic nerve function, the frequency of ICA was increased in patients with CF-SG, and the levels of ICA and CF-SG were found to be correlated, whereas CF-ADM were associated with sympathetic nerve failure. In addition, five previously GADab negative IDDM patients became positive after 1015 years i.e. many years after the clinical diagnosis of IDDM.

Evidently, this study does not support the hypothesis that persistent GAD-ab are associated with diabetic neuropathy [11]. However, autonomic and not peripheral nerve function was evaluated in our study. Diabetic autonomic neuropathy occurs more frequently with peripheral neuropathy $[28,29]$ but may dissociate $[30,31]$. Thus, this study cannot completely rule out the possibility of a link between GAD-ab and neuropathy; further studies will be required in which patients are assessed for peripheral nerve function and GAD$a b$. The putative correlation between neuropathy and GAD-ab [11] might, however, have reflected the duration of diabetes and not neuropathy as was recently suggested in a preliminary report [32]. Signs of peripheral [33] and autonomic $[34,35]$ dysfunction are known to increase with the duration of diabetes. In the present study, however, GAD-ab were detected in patients with a long duration of IDDM without signs of neuropathy. The detection of these GAD-ab in long-term IDDM patients is in agreement with recent observations $[10,12,32]$.

Before rejecting the hypothesis of an association between GAD-ab and neuropathy, the importance of GAD isoforms should be considered. GAD-65 is expressed in human pancreatic islets [36] and is a major islet cell antigen against which autoantibodies are formed in IDDM patients [23]. In contrast to pancreatic islets, GAD-65 and GAD-67 are expressed in nerve tissue from different species, including humans [37]. Though GAD-67 antibodies may be detected at the onset of IDDM, GAD-67 antibodies do not occur without GAD-65 antibodies [23]. The hypothesis that GAD-ab and neuropathy are associated was based on findings in eight IDDM patients using a nitrocellulose dot-blot assay where the GAD-65 and GAD-67 isoforms were produced by bacterial expression [11]. Dotblot assays are only semiquantitative, however, and often complicated by background problems due to immunoglobulins interacting with low affinity binding. The reported GAD 67 reactivity in six of the eight GAD-ab positive patients may rather have reflected cross-reactivity. Therefore, in our opinion, it is unlikely that there is a group of neuropathy prone diabetic patients who only secrete GAD-67 ab. Besides differences in methodology (our assay considered GAD 65 only), in contrast to nine long-term IDDM patients with neuropathy compared with four IDDM patients without [11], we compared 55 IDDM patients with and 40 without neuropathy and found that $38 \%$ in each group demonstrated GAD-ab. In addition, in our study, GAD-ab and autonomic nerve antibodies were unrelated also arguing against an association between GAD-ab and neuropathy. The lack of GAD-ab in NIDDM also obscures the hypothesis that GAD-ab are linked to diabetic neuropathy; autonomic neuropathy is frequently observed in NIDDM [22].

A salient finding was the discovery that GAD-ab could be detected in IDDM patients lacking GAD-ab 10-13 years earlier (prospective study). Accordingly, GAD-ab may develop after many years of IDDM. A "new" development of GAD-ab, could also be the rational behind the presence of GAD-ab in our cross-sectionally tested material. In the cross-sectional material, some patients were tested for C-peptide and found to be negative [34]. Hence, it is unlikely that preserved beta-cell function explained the occurrence of GAD$\mathrm{ab}$ in these patients; lack of preserved beta-cell function has also been noticed in other long-term IDDM patients with GAD-ab $[9,10]$. Our finding that GADab can be detected years after diagnosis of IDDM in patients previously negative (prospective series of pa- 
tients), may not neccessarily challenge the concept of $\mathrm{GAD}$ as a major antigen involved in the pathogenesis of IDDM $[3,38,39]$. The frequency of GAD-ab is high at the clinical diagnosis of IDDM [40] and then decreases [9]. Autoimmunity directed against GAD may fade in parallel with initial beta-cell loss during IDDM. Other GAD containing structures, not neccessarily nerves, may then induce a memory response when exposed to immune competent cells. This would stimulate a second development of GAD-ab or an increased level of GAD-ab in patients with GAD-ab. Such a mechanism would explain the lack of GAD-ab in longterm NIDDM patients. The commencement of NIDDM is not associated with GAD-ab; GAD-ab in "NIDDM patients" indicate the diagnosis of IDDM $[41,42]$.

In our original communication [21], CF-SG were not separated from CF-ADM; the two sympathetic nerve antibodies taken together were associated with preserved autonomic nerve function. It now appears that CF-SG and not CF-ADM are responsible for this paradoxical association. Analogous to ICA in preIDDM subjects [4], CF-SG may precede autonomic neuropathy. This is not contradicted by the low frequency of CF-SG in the first study of the prospectively followed patients; lack of CF-SG in these samples may have been a consequence of the long storage period, or the sensitivity of the assay, or both. The possibility that persistent ICA in combination with CF-SG signifies a specific sub-group of autoimmune IDDM must be seriously considered.

Recently, CF-SG were observed in 6 of $37(\approx 20 \%)$ of IDDM patients with symptoms and signs of autonomic neuropathy compared with none ( 0 of 25$)$ without [43]. The association between autonomic dysfunction and CF-SG seemed to be related rather to symptoms, however, than to signs of autonomic neuropathy (patients with signs but without symptoms lacked CFSG). Due to our previous experience of the difficulties in validating symptoms of autonomic neuropathy [22], symptoms were not evaluated in this study. In the study of Zanone et al. [43], CF-SG, as well as CF-ADM and $\mathrm{CF}-\mathrm{V}$ (reported in frequencies similar to those in our study), were assumed to be related to GAD or GAD$\mathrm{ab}$, or both. This suggestion was not confirmed in our study. GAD-ab were neither associated with autonomic neuropathy nor with CF-SG, CF-ADM, and CF$\mathrm{V}$; however, GAD-ab were related to IDDM, to ICA, could be detected in IDDM patients with a surprisingly long duration of diabetes, and could appear in IDDM patients who did not demonstrate GAD-ab 10-13 years earlier. In our study, CF-ADM, in contrast to CF-SG, were associated with signs of sympathetic failure [44] i. e. blood pressure falls after tilt and abnormally low brake indices. Accordingly, CF-ADM might be a phenomenon related to adrenal medullitis [45] and adrenal medulla fibrosis [46], putative causes of sympathetic failure in diabetic patients.
Acknowledgements. This work was supported by grants from the Swedish Medical Research Council (07 507), Swedish Diabetes Association, Lundström Foundation, Hoechst Fund for Diabetes Research, Nordisk Insulin Foundation, Lund University Funds, Lion Club International District 101, Research Funds Malmö General Hospital, Malmö Diabetes Association, Child Diabetes Fund, and by NIH grant 30987 (to S. R.). The current address for Dr Rabinowe is Department of Medicine, Sinai Hospital, 6767 West Outer Drive, Detroit, MI-48235-2899, USA.

\section{References}

1. Bækkeskov S, Aanstoot H-J, Christgau S et al. (1990) Identification of the $64 \mathrm{~K}$ autoantigen in insulin-dependent diabetes as the GABA-synthesizing enzyme glutamic acid decarboxylase. Nature (Lond) 347: 151-156

2. Bækkeskov S, Nielsen JH, Marner B, Bilde T, Ludvigsson J, Lernmark $\AA$ (1982) Autoantibodies in newly diagnosed diabetic children immunoprecipitate human pancreatic islet cell proteins. Nature (Lond) 298: 167-169

3. Bækkeskov S, Landin M, Kristensen JK et al. (1987) Antibodies to a $64000 \mathrm{Mr}$ human islet cell antigen precede the clinical onset of insulin dependent diabetes. J Clin Invest 79: 926-934

4. Srikanta S, Ganda OP, Gleason RE, Jackson RA, Soeldner JS, Eisenbarth GS (1984) Pre-type 1 diabetes. Linear loss beta cell response to intravenous glucose. Diabetes 33: 717720

5. Landin-Olsson M, Karlsson A, Dahlquist G, Blom L, Lernmark $\AA$, Sundkvist $G$ (1989) Islet cell and other organ-specific autoantibodies in all children developing type 1 (insulindependent) diabetes mellitus in Sweden during one year and in matched controls. Diabetologia 32: 387-395

6. Kolb H, Dannehl K, Grüneklee D et al. (1988) Prospective analysis of islet cell antibodies in children with type 1 (insulin-dependent) diabetes. Diabetologia 31: 189-194

7. Wallensteen M, Dahlquist G, Persson B et al. (1988) Factors influencing the magnitude, duration, and rate of fall of B-cell function in type 1 (insulin-dependent) diabetes children followed for two years from their clinical diagnosis. Diabetologia 31: 664-669

8. Peig M, Gomis R, Ercilla G, Casamitjana R, Bottazzo GF, Pujol-Borell $\mathrm{R}$ (1989) Correlation between residual $\beta$-cell function and islet cell antibodies in newly diagnosed type 1 diabetes. Follow up study. Diabetes 38: 1396-1401

9. Christie MR, Daneman D, Champagne P, Delovitch TL (1990) Persistence of serum antibodies to $64,000-\mathrm{M}_{\mathrm{r}}$ islet cell protein after onset of type 1 diabetes. Diabetes 39:653-656

10. Rowley MJ, Mackay IR, Chen Q-Y, Knowles WJ, Zimmet PZ (1992) Antibodies to glutamic acid decarboxylase discriminate major types of diabetes mellitus. Diabetes 41:548551

11. Kaufman DL, Erlander MG, Clare-Salzler M, Atkinson MA, Maclaren NK, Tobin AJ (1992) Autoimmunity to two forms of glutamate decarboxylase in insulin-dependent diabetes mellitus. J Clin Invest 89: 283-292

12. Kawasaki E, Moriuchi R, Takino H et al. (1992) Autoantibodies to $64,000-\mathrm{M}_{\mathrm{r}}$ islet cell protein in long-term type 1 (insulin-dependent) diabetic patients. Diabetologia 35: 748-752

13. Sorenson RL, Garry DG, Brelje TC (1991) Structural and functional considerations of GABA in islets of Langerhans, $\beta$-cells and nerves. Diabetes 40: 1365-1374

14. Duchen LW, Anjorin A, Watkins PJ, Mackay JD (1980) Pathology of autonomic neuropathy in diabetes mellitus. Ann Intern Med 92: 301-303 
15. Guy RJC, Richards F, Edmonds ME, Watkins PJ (1984) Diabetic autonomic neuropathy and iritis: an association suggesting an immunological cause. BMJ 289: 343-345

16. Gilbey SG, Guy RJC, Jones H, Vergani H, Watkins PJ (1986) Diabetes and autonomic neuropathy: an immunological association? Diabetic Med 3: 241-245

17. Gilbey SG, Hussain MJ, Watkins PJ, Vergani D (1988) Cellmediated immunity and symptomatic diabetic neuropathy. Diabetic Med 5: 845-848

18. Brown FM, Kamalesh M, Adri S, Rabinowe SL (1988) Antiadrenal medullary antibodies in IDDM subjects and subjects at high risk of developing IDDM. Diabetes Care 11: 30-33

19. Brown FM, Brink SJ, Freeman R, Rabinowe SL (1989) Antisympathetic nervous system autoantibodies. Diminished catecholamines with orthostatis. Diabetes 38: 938-941

20. Rabinowe SL, Brown FM, Watts M, Smith AM (1990) Complement fixing antibodies to sympathetic and parasympathetic tissues in IDDM. Autonomic brake index and heart rate variation. Diabetes Care 13: 1084-1088

21. Sundkvist G, Lind P, Bergström B, Lilja B, Rabinowe S (1991) Autonomic nervous autoantibodies and autonomic nerve function in type 1 and type 2 diabetic patients. J Intern Med 229: 505-510

22. Bergström B, Lilja B, Österlin S, Sundkvist G (1990) Autonomic neuropathy in non-insulin dependent (Type 2) diabetes mellitus. Possible influence of obesity. J Intern Med 227: $57-63$

23. Velloso LA, Kämpe O, Hallberg A, Christmanson L, Betsholtz C, Karlsson FA (1993) Demonstration of GAD-65 as the main immunogenic isoform of glutamate decarboxylase in type 1 diabetes and determination of autoantibodies using a radioligand produced by eukaryotic expression. J Clin Invest 91: 2084-2090

24. Landin-Olsson M, Sundkvist G, Lernmark $\AA$ (1987) Prolonged incubation in the two-colour immunofluorescence test increases the prevalence and titres of islet cell antibodies in type 1 (insulin-dependent) diabetes mellitus. Diabetologia 30: 327-332

25. Brown FM, Watts M, Rabinowe SL (1991) Aggregation of subclinical autonomic nervous system dysfunction and autoantibodies in families with type 1 diabetes. Diabetes 40 : 1611-1614

26. Sundkvist G, Almér L-O, Lilja B (1979) Respiratory influence on heart rate in diabetes mellitus. BMJ 1:924-925

27. Sundkvist G, Lilja B, Almér L-O (1980) Abnormal diastolic blood pressure and heart rate reactions to tilting in diabetes mellitus. Diabetologia 19: 433-438

28. Sundkvist G (1981) Autonomic nervous function in asymptomatic diabetic patients with signs of peripheral neuropathy. Diabetes Care 4: 529-534

29. Neil HAW, Thompson AV, John S, McCarthy ST, Mann JI (1989) Diabetic autonomic neuropathy: the prevalence of impaired heart rate variability in a geographically defined population. Diabetic Med 6: 20-24

30. Bergström B, Mattiasson I, Rosén I, Lilja B, Sundkvist G (1989) Platelet sodium and potassium adenosine triphosphatase activity and norepinephrine efflux rate in relation to autonomic and peripheral nerve function in insulin dependent diabetic patients. J Intern Med 225: 185-190
31. Sundkvist G, Armstrong FM, Brảdbury JE et al. (1992) Peripheral and autonomic nerve function in 259 diabetic patients with peripheral neuropathy treated with ponalrestat (an aldose reductase inhibitor) or placebo for 18 months. $\mathbf{J}$ Diab Comp 6: 123-130

32. Tuomi T, Zimmet PZ, Rowley MJ, Serjeantson SW, Mackay IR (1993) Persisting antibodies to glutamic acid decarboxylase in type 1 (insulin-dependent) diabetes mellitus are not associated with neuropathy. Diabetologia 36: 685 (Letter)

33. Pirart J (1978) Diabetes mellitus and its degenerative complications: a prospective study of 4,400 patients observed between 1947 and 1973. Diabetes Care 1: 168-188

34. Masaoka S, Lev-Ran A, Hill LR, Vakil G, Hon EHG (1985) Heart rate variability in diabetes: relationship to age and duration of the disease. Diabetes Care 8: 64-68

35. Bergström B, Lilja B, Österlin S, Sundkvist G (1987) Autonomic neuropathy in type 1 diabetes: influence of duration and other diabetic complications. Acta Med Scand 222: 147 154

36. Björk E, Kämpe O, Karlsson FA et al. (1992) Glucose regulation of the autoantigen GAD 65 in human pancreatic islets. J Clin Endocrinol Metab 75: 1574-1576

37. Erlander M, Tillakaratne N, Feldblum S, Patel N, Tobin AJ (1991) Two genes encode distinct glutamate decarboxylases. Neuron 7: 91-100

38. Atkinson MA, Maclaren NK, Scharp DW, Lacy PE, Riley WJ (1990) $64000 \mathrm{Mr}$ autoantibodies as predictors of insulindependent diabetes. Lancet 335: 1357-1360

39. Bärmeier H, McCulloch DK, Neifing JL et al. (1991) Risk for developing type 1 (insulin-dependent) diabetes mellitus and the presence of islet $64 \mathrm{~K}$ antibodies. Diabetologia 34: 727733

40. Christie M, Landin-Olsson M, Sundkvist G, Dahlquist G, Lernmark $\AA$, Bækkeskov S (1988) Antibodies to a Mr-64000 islet cell protein in Swedish children with newly diagnosed type 1 (insulin-dependent) diabetes. Diabetologia 31: 597602

41. Hagopian WA, Karlsen AE, Gottsäter A et al. (1993) Quantative assay using recombinant human islet glutamic acid decarboxylase (GAD65) shows that $64 \mathrm{~K}$ autoantibody positivity at onset predicts diabetes type. J Clin Invest 91: 368-374

42. Tuomi T, Groop LC, Zimmet PZ, Rowley MJ, Knowles W, Mackay IR (1993) Antibodies to glutamic acid decarboxylase reveal latent autoimmune diabetes mellitus in adults with a non-insulin-dependent onset of disease. Diabetes 42: $359-362$

43. Zanone MM, Peakman M, Purewal T, Watkins PJ, Vergani D (1993) Autoantibodies to nervous tissue structures are associated with autonomic neuropathy in type 1 (insulin-dependent) diabetes mellitus. Diabetologia 36: 564-569

44. Bergström B, Manhem P, Bramnert M, Lilja B, Sundkvist G (1989) Impaired responses of plasma catecholamines to exercise in diabetic patients with abnormal heart rate reactions to tilt. Clin Phys 9: 259-267

45. Brown MF, Smith AM, Longway S, Rabinowe SL (1990) Adrenal medullitis in type I diabetes. J Clin Endocrinol Metab 71: 1491-1495

46. Brown FM, Zuckerman M, Longway S, Rabinowe SL (1989) Adrenal medullary fibrosis in IDDM of long duration. Diabetes Care 12: 494-497 